\title{
MEMAHAMI KOMUNIKASI PENYESUAIAN DIRI ANAK TUNARUNGU DI SEKOLAH INKLUSI
}

\author{
Alysha Paxia Susilo
}

\begin{abstract}
Deaf and hard-hearing children that goes to inclusive school often find difficulties in adjusting themselves in inclusive school environment. this several factors are affecting this condition including psychosocial, communication, and behavioral factors that they get from the school environment. Communication of anxiety and uncertainty reduction is the early stage of how deaf and hard hearing children can adapt themselves in inclusive school environment. the aim of this research is to understand the narrative of deaf and hard-hearing children of their selfadjustment in inclusive school through their strategy of anxiety and uncertainty reduction. The type of this research is qualitative research. this research analyze and interpret some written text about deaf and hard-hearing children's experience of adjustment in inclusive school. this research is using Mishler's narrative analysis.

Result of this research shows different narratives of deaf and hard-hearing children's self adjustment in inclusive school. those narratives are complete withdrawal from school environment, passive observation and only focusing on school subjects. only close with their deaf and hardhearing friendsa, finding close friends that diesnt require any special needs, and the last one which is getting external support from teachers and friends in the inclusive school environment. moreover, they use passive and interactive technique in information-seeking to reduce their uncertainty. they are most likely use multiple modal of communication and highly dependent on the usage of social media as tools to seek information and communicate. in addition, the role of social support from their close relatives is highly affecting their initiatives in reducing anxiety and uncertainty that they experience

based on the results, researcher suggests that people that involves in inclusive school settings including parents, teachers, and friends to always support and help children with deaf and hearing-impaired condition physically and psychologically to adapt in inclusive school environments. without significant support and help, initiatives of reducing anxiety and uncertainty will not be effective thus can worsen their self adjustment in inclusive school.
\end{abstract}

Keywords: Deaf and Hard-hearing children, uncertainty and anxiety reduction communication, self adjustment

\section{PENDAHULUAN}

Penyesuaian diri anak penderita tunarungu di dalam lingkungan sekolah inklusi kerapmenjadi masalah dalam perkembangan anak di sekolah.
Siswa tunarungu yang bersekolah di sekolah inklusi memiliki permasalahan penyesuaian diri yang lebih besar dibanding siswa tunarungu yang belajar di sekolah luar biasa (Adwiasa dan Muryantinah, 2013:2) hal ini disebabkan karena, 
adanya kompetisi di dalam sekolah inklusi yang dialami oleh siswa tunarungu menyebabkan munculnya permasalahan penyesuaian diri.

Siswa tunarungu memiliki masalah psikososial yang lebih kecil ketika di sekolah inklusi dibanding ketika di sekolah luar biasa. Hal ini dikarenakan sekolah inklusi memberikan akses yang lebih baik terhadap teman sebaya yang normal dan dukungan dari para spesialis yang baik dibandingkan di sekolah luar biasa. Hal ini menghasilkan kinerja anak di sekolah yang lebih baik serta potensi anak yang bisa lebih terlihat tanpa harus mengisolasikan diri dengan anak-anak lain yang sama dengan dirinya.

Pentingnya peran manajemen komunikasi pengurangan kecemasan dan ketidakpastian yang dirasakan saat menyesuaikan diri menjadi faktor utama bagaimana dirinya bisa beradaptasi di lingkungan sekolah inklusi. Komunikasi pengurangan ketidakpastian menjadi faktor berhasil tidaknya penyeseuaian diri seseorang dalam lingkungan baik dari lingkungan asing maupun lingkunganminoritas yang bisamenambah usaha penyesuaian diri di lingkungan tersebut.

\section{RUMUSAN MASALAH}

Peneliti ingin mengetahui bagaimana komunikasi penyesuaian diri yang dilakukan anak tunarungu di sekolah inklusi?

\section{TUJUAN PENELITIAN}

Tujuan dari penelitian ini adalah untuk memahami narasi penyesuaian diri anak tunarungu di sekolah inklusi melalui strategi mereka dalam mengurangi kecemasan dan ketidakpastian.

\section{KERANGKA PEMIKIRAN TEORITIS}

Melihat fenomena yang terjadi pada proses adpatasi dan pengelolaan ketidakpastian pada anak siswa tunarungu di lingkungan sekolah inklusi, peneliti menggunakan paradigma ilmiah. Paradigma ilmiah biasa dikenal juga dengan paradigma interpretif. Penelitian interpretif tidak hanya berasumsi bahwa realitas bersifat eksternal terhadap manusia. tujuan penelitian interpretif bukan untuk melakukan prediksi, tetapi memahami dan menerangkan perilaku manusia, bila peneliti interpretif melihat budaya sebagai diciptakan dan dipelihara melalui komunikasi . Oleh karena itu, paradigma interpreftif sebagai dasar kerangka berpikir, sangat ideal untuk melihat dan memahami perilaku-perilaku masyarakat yang muncul dalam memaknai dan memahami proses komunikasi interpersonal anak tunarungu dalam mengurangi kecemasan dan ketidakpastian terhadap penyesuaian diri mereka di lingkungan sekolah inklusi.

Teori reduksi ketidakpastian mencari penjelasan bagaimana kita berkomunikasi apabila kita tidak pasti dengan lingkungan kita (Berger dan Baradac dalam Budyatna, 2015 : 140) teori reduksi ketidakpastian berfokus pada bagaimana orang tak dikenal atau strangers berkomunikasi. Teori ini terbatas bagi perilaku dalam sebuah interaksi awal (Berger dan Calabrase dalam Budyatna, 2015 : 140 ) Teori ini menyoroti ketidakpastian sebagai kekuatan kausal membentuk perilaku komunikasi dan meningkatkan prediksi-prediksinya yang dapat diuukur tentang bagaimana orang berperilaku apabila mereka merasa tidak pasti. Teori ini melakukan identifikasi prinsip-prinsip komunikasi atarpribadi yang menyamaratakan semua peristiwa khusus (Budyatna, 2011 : 139-141)

kontekstualisasi dalam penelitian ini adalah bagaimana anak dengan tunarungu berusaha untuk memprediksi dan menjelaskan lingkunganlingkungan mereka dalam hal menyesuaikan diri di lingkungan sekolah inklusi. Bagaimana strategi mereka berkomunikasi dalam mencari informasi untuk mengatasi kesulitan beradaptasi mereka di lingkungan tersebut dan bagaimana mereka memprediksi situasi yang mereka hadapi saat 
menemukan ketidakpastian tersebut.

Pemikiran teoritik yang memiliki relasi dengan pengelolaan ketidakpastian dan kecemasan dalam komunikasi di lingkungan baru adalah Anxiety/uncertainty management theory dari Gudykunst yang memfokuskan pada pertemuan kultural (cultural encounters) antara in-groups dengan strangers (individu-individu yang ada dalam situasi, tetapi bukan in-group). Gudykunts mengarahkan teorinya untuk dapat diterapkan dalam setiap situasi dimana perbedaan-perbedaan antara individu dengan individu lain menciptakan keraguan dan kekhawatiran. Ia berasumsi bahwa paling tidak satu orang dalam pertemuan antar budaya strangers atau orang asing. Melalui serangkaian krisis pada tahap-tahap awal, orang asing tersebut mengalami ketidakpastian (uncertainty) dan kecemasan (anxiety) mereka merasa tidak nyaman dan tidak patsi tentang bagaimana harus berperilaku.

Melalui teori ini peneliti menemukan relevansinya akan bagaimana kemampuan individu tunarungu dalam menagatur kecemasan dan ketidakpastian yang terjadi di dalam diri mereka untuk berkomunikasi secara efektif dan menyesuaikan diri di lingkungan sekolah inklusi yangmemiliki nilai, aturan, serta lingkungan yang berbeda darinya, bagaimana individu tunarungu tersebut juga menyiapkan strategi komunikasi yang tepat untuk bisa menyesuaikan diri di lingkungan tersebut.

\section{METODE PENELITIAN}

Metode penelitian yang digunakan dalam penelitian ini adalah Naratif. Penelitian naratif adalah laporan bersifat narasi yang menceritakan urutan peristiwa secara terperinci. Dalam desain penelitian naratif, peneliti menggambarkan kehidupan individu, mengumpulkan cerita tentang kehidupan orang-orang dan menulis narasi pengalaman individu (Connelly dan Clandinin, 1990). Kriteria subjek penelitian adalah anak tunarungu usia sekolah ( 6- 18 tahun) yang bersekolah di Sekolah Inklusi. Teknik pengumpulan data menggunakan pengumpulan teks narasi oleh anak tunarungu serta wawancara mendalam. Analisis data menggunakan analisis naratif Mishler dengan berpanduan pada model Labov. Analisis pertama-tama yaitu merekapitulasi narasi dari informan, merekonstruksi cerita sesuai dengan kronologis yaitu abstrak, orientasi, komplikasi, evaluasi, resolusi, dan koda, lalumengidentifikasi kesamaan dan keunikan pola dari setiap cerita, dan yang terakhir yaitu menyimpulkan narasi.

\section{HASIL DAN PEMBAHASAN}

Narasi Nadira berfokus pada ketidakmampuan dirinya dalam menyesuaikan diri di lingkungan sekolah inklusi. Narasi yang dituliskan oleh Nadira seringkali berfokus pada permasalahan-permasalahan yang terjadi dalam pengalamannya menyesuaikan diri dan bagaimana dirinya tidak dapat mengatasi setiap masalahmasalah tersebut. Permasalahan yang terjadi seringkali berasal dari teman-temannya di sekolah yang tidak mau membantu dirinya dan pihak sekolah yang terkesan tidak mendukung atau bahkan membantu Nadira dalam mengatasi kesulitan-kesulitan yang dialaminya. Narasi Nadira juga menunjukkan bahwa dirinya tidak bisa melakukan manajemen pengurangan kecemasan dan ketidakpastian dengan baik karena konsep dirinya yang cenderung tidak percaya diri dan lebih sering menghindar dari peristiwa-peristiwa yang dialaminya.

Narasi Izzan bercerita tentang bagaimana ekspetasi dirinya terhadap bersekolah di sekolah inklusi tidak terpenuhi. Narasi Izzan lebih berfokus kepada bagaimana caranya bertahan di sekolah inklusi tanpa harus berhadapan dengan masalah-masalah kecil yang membuatnya tidak nyaman. Selain itu, Narasi yang disampaikan juga berpusat di sekitar bagaimana Izzan membangun batasan-batasan baik dengan guru dan dengan 
teman-temannya untuk menjaga trauma yang dialaminya saat masuk ke sekolah inklusi. Izzan juga menjabarkan bagaimana cara-caranya ia menyesuaikan diri di sekolah tanpa harus banyak beirnteraksi dengan banyak teman-teman dan guru-gurunya yang ia tidak sukai.

Narasi Madhan bercerita tentang ketidaksukaan Madhan dalam bersekolah di sekolah Inklusi. Semenjak di sekolah Inklusi, Madhan sering dirundungi atau di bully oleh teman-teman dan kakak kelasnya di sekolah karena dirinya tunarungu. Narasi Madhan juga berfokus kepada bagaimana akhirnya Madhan bisa menyesuaikan diri di sekolah dengan lebih tidak peduli dengan sekitar dan hanya fokus kepada pelajaran. Narasi Madhan juga berfokus pada bagaimana orang-orang sekitarnya, khususnya ibunya, mendorongnya agar tidak takut lagi masuk sekolah dan membangun kepercayaan dirinya untuk bisa meneruskan bersekolah di sekolah Inklusi.

Narasi Obith bercerita lebih banyak tentang bagaimana dirinya menyelesaikan masalah-masalah yang dialaminya terhadap teman-teman sekelasnya yang sering meremehkan dan menyepelekan kemampuan obith dalam mengerjakan tugas dan mengikuti pelajaran. Narasi yang diceritakan Obith juga berfokus pada perubahan persepsi dirinya yang menganggap pada awalnya bahwa di sekolah inklusi, dirinya bisa mendapatkan banyak teman baru yang berbeda dengan dirinya tetapi ekspetasi tersebut tidak terpenuhi dan bahkan meleset jauh dari perkiraannya. Selain itu, Narasi Obith juga banyak menceritakan tentang bagaimana guru pembimbingnya membantunya untuk mengatasi berbagai kesulitan yang dia alami selama dirinya mencoba menyesuaikan diri di sekolah tersebut

Narasi yang diceritakan oleh Jihan berfokus dengan bagaimana mencari sahabat-sahabat dekat yang bisa diajak berteman olehnya sangat membantunya dalammenyesuaikan diri di sekolah
Inklusi. Selain itu, Narasi ini lebih banyak memaparkan tentang masalah Jihan yang diacuhkan oleh teman-temannya, dan perjuangan dirinya untuk mencari teman yang ingin berteman dengan dirinya. Selain itu, Narasi Jihan juga berfokus pada proses penyesuaian dirinya di sekolah inklusi dan mengatasi masalah-masalah khususnya dalam pertemanan.

Narasi yang diceritakan oleh Rania lebih berfokus pada bagaimana dirinya sebagai anak tunarungu mencoba menjadi seperti anak yang normal di sekolah inklusinya. Mempunyai julukan sebagai Anak berkebutuhan Khusus di sekolahnya membuat Rania jauh lebih tidak nyaman untuk belajar ataupun bergaul dengan teman-temannya. Oleh karena itu, Narasi ini lebih bercerita tentang bagaimana Rania mencoba menghilangkan julukan tersebut dengan mencoba berbagai cara untuk belajar dan bermain seperti teman-temannya yang lain dengan berusaha tidak menunjukkan ketunarunguannya di depan teman atau gurunya serta menghindar dari perhatianperhatian berlebih yang ditujukan kepadanya oleh teman dan guru-gurunya.

Narasi Afit lebih banyak berfokus pada bagaimana teman-teman dan guru-guru Afit ada untuk membantu dirinya dalam berbagai kesulitan dan kendala dalam diri Afit menyesuaikan di sekolah Inklusi. Narasi ini lebih banyak bercerita tentang bagaimana konsep diri Afit yang positif dalam menghadapi segala kesulitan yang dirinya hadapi dan motivasi yang dirinya miliki untuk menghadapi ketidakpastian yang dialaminya. Narasi Afit juga menunjukkan penyesuaian diri yang cukup cepat dibanding subjek yang lain karena bantuan teman-teman dan guru-gurunya yang mendukungnya dengan baik.

terdapat 3 pola komunikasi pengurangan kecemasan dan ketidakpastian dalam proses penyesuaian diri para subjek di sekolah inklusi. Pola tersebut sangat berpengaruh kuat dengan konsep diri dan motivasi atau dorongan eksternal dalam proses penyesuaian diri para subjek di 
lingkungan sekolah inklusi. Berikut dijabarkan ketiga pola komunikasi pengurangan ketidakpastian dalam proses penyesuaian diri anak tunarungu di sekolah inklusi

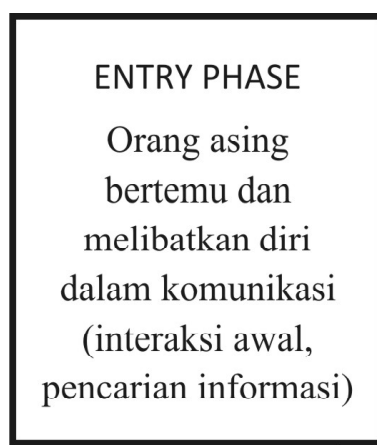

tersebut di sekolah.

2. Narasi ketiga adalah narasi tentang bagaimana akhirnya anak tunarungu tersebut memilih untuk hanya fokus kepada hal yang penting saja yaitu pelajaran, cenderung untuk membuat batasan dan mengabaikan lingkungan sekolah yang menurutnya tidak kondusif, dan melakukan pencarian informasi yang esensial hanya dengan observasi semata. Hal ini disebabkan oleh tidak kondusifnya lingkungan sekolah yang sebagian besar datang dari pergaulan di sekolah tersebut.

\section{PENUTUP}

\section{Kesimpulan}

Berdasarkan hasil yang didapatkan, narasi anak tunarungu dalam proses mereka menyesuaikan diri berbeda-beda. Terdapat enam kesimpulannarasi dari tujuh informan yang diteliti. Berikut adalah kesimpulan dari narasi tersebut :

1. Narasi pertama dan kedua menjelaskan tentang bagaimana akhirnya anak tunarungu tersebut lebih memilih untuk menarik diri dari sekolah dan berusaha untuk tidak banyak terlibat dalam lingkungan sekolah tersebut. hal ini disebabkan oleh keadaan lingkungan sekolah yang tidak mendukung baik teman yang kerap mendeskriminasi dan guru yang tidak peduli dengan perkembangan anak
EXIT PHASE

Individu mempertimbangkan apakah akan melanjutkan relasi tersebut atau tidak

3. Narasi keempat menjelaskan tentang bagaimana akhirnya anak tunarungu tersebut memilih untuk berteman hanya dengan yang tunarungu saja dan juga dengan guru pembimbingnya saja. Anak tersebut menutup kemungkinan untuk berteman dan lebih dekat dengan teman dan guru yang tidak membutuhkan bantuan khusus karena ia mendapatkan respon yang tidak pernah menyenangkan dalam bergaul dengan mereka di lingkungan sekolah tersebut. 
4. Narasi kelima menjelaskan tentang bagaimana usaha anak tunarungu tersebut dalam mencari sahabat dekat yang bisa mengerti dan membantu dirinya dalam menyesuaikan diri di lingkungan sekolah inklusi karena dengan bantuan teman dekatnya ia bisa lebih mengerti bagaimana caranya bersikap dan berperilaku di depan anak tanpa kebutuhan khusus sekaligus menjalin intimasi yang lebih dekat dengan guru dan teman-temannya.

5. Narasi keenam menjelaskan tentang bagaimana usaha anak tunarungu ini untuk berkonformitas menjadi seperti anak tanpa kebutuhan khusus. Penggunaan sosial media yang gencar, berusaha berbicara, bersikap, dan berperilaku layaknya orang tanpa bantuan khusus, dan tidak mau disebut anak berkebutuhan khusus agar dirinya tidak lagi di deskriminasi di lingkungan sekolahnya dan tidak direndahkan lagi kemampuannya oleh teman dan guru-gurunya.

6. Narasi terakhir menjelaskan tentang bagaimana pengaruh dukungan sosial yang positif dari guru dan teman-teman di lingkungan sekolah inklusi tersebut bisa membantu anak tunarungu ini menjadi percaya diri dan bisa menyesuaikan diri di lingkungan sekolah tersebut. Bantuan positif yang diberikan oleh lingkungan sekolah tersebut dangat berdampak signifikan terhadap proses penyesuaian diri yang dilakukan oleh anak tunarungu ini sehingga ia bisa sukses beradaptasi walaupun dengan banyak kekurangan dari dirinya.

Berdasarkan penelitian, penulis menjelaskan beberapa implikasi yang bermanfaat dalam bidang teoritis praktis, serta sosial.

\section{Implikasi Teoritis}

Secara teoritis, penelitian ini dapat memperkaya kajian komunikasi antarpribadi dalam konteks komunikasi pengurangan kecemasan dan ketidakpastian yang dialami oleh orang berkebutuhan khusus di lingkungan yang tidak berkebutuhan khusus. Kajian tersebut mengenai bagaimana penyesuaian diri anak tunarungu di sekolah inklusi. Bagaimana anak tunarungu mengatasi kecemasan dan ketidakpastiannya dijelaskan dalam Teori Pengurangan Ketidakpastian dan Teori Manajemen Pengurangan Kecemasan dan Ketidakpastian.

Teori Pengurangan Ketidakpastian dan Teori Manajeman Pengelolaan Kecemasan dan Ketidakpastian menjelaskan tentang ketidakpastian yang terjadi dalam diri anak tunarungu dan strategi apa yang digunakan oleh anak tunarungu untuk mengurangi ketidakpastian yang dialaminya di sekolah inklusi. Penelitian ini memberikan tambahan bagi teori ini tentang letak dimana kecemasan dan ketidakpastian yang ada dalam proses penyesuaian diri. Posisi kecemasan dan ketidakpastian dalam penyesuaian diri berada pada fase rintangan dan menjadi hambatan dalam konsep diri atau evaluasi untuk mencapai resolusi atau penyelesaian masalah yang terjadi. Ketika anak tunarungu mengalami kecemasan dan ketidakpastian, dua hal tersebut termanifestasi sebagai bentuk hambatan oleh mereka yang akhirnya mempengaruhi bagaimana cara mereka melihat diri mereka dalam posisi di lingkungan sekolah inklusi tersebut dan akhirnya juga mempengaruhi apa yang dilakukan sebagai resolusi mereka dalam menyesuaikan diri di lingkungan sekolah inklusi tersebut. kecemasan dan ketidakpastian sangat menentukan langkah mereka selanjutnya dalam proses adaptasi tersebut. selain itu, respon eksternal yang didapatkan juga sangat mempengaruhi konsep diri atau evaluasi diri yang terjadi sehingga mempengaruhi juga tindakan-tindakan yang diambil dalam udaha anak tunarungu tersebut dalam menyesuaikan diri di lingkungan sekolah inklusi. 


\section{Implikasi Praktis}

Penelitian ini dapat memberikan referensi bagi orangtua, guru, serta lingkungan sekolah inklusi yang langsung terlibat dalam hidup anak tunarungu dalam bagaimana seharusnya komunikasi antarpribadi anak tersebut dalam penyesuaian dirinya di sekolah inklusi. Penelitian ini menunjukkan bahwa penggunaan moda yang bervariasi serta media-media pembantu seperti media sosial sangat membantu anak tunarungu dalam mengatasi kecemasan dan ketidakpastian yang dialaminya di lingkungan sekolah inklusi. Sistem sekolah yang menyediakan guru pendamping juga bisa berdampak lebih baik terhadap penyesuaian diri anak daripada sistem sekolah yang menggunakan metode inklusi penuh. Interaksi antar pribadi juga sangat berpengaruh terhadap pengurangan kecemasan dan ketidakpastian anak tersebut di sekolah inklusi.

\section{Implikasi Sosial}

Penelitian ini dapat memberikan sebagian jawaban dari permasalahan penyesuaian diri anak tunarungu di sekolah inklusi. Penelitian ini menunjukkan bahwa penyesuaian diri anak tunarungu di sekolah inklusi khususnya dalam tahap pengurangan kecemasan dan ketidakpastian sangat bergantung dari motivasi yang didapatkan oleh mereka dari lingkungan eksternal mereka. Lingkungan eksternal mereka dapat menjadi dorongan tersendiri atau bahkan menjadi penghambat dalam apakah mereka mau dan bisa menyesuaikan diri di sekolah inklusi tersebut. penelitian ini bisa menjadi penyadar bagi masyarakat bahwa anak tunarungu butuh dukungan dan bantuan yang khusus agar mereka bisa menjalani kehidupannya seperti orang normal khususnya di lingkungan sekolah inklusi.

\section{DAFTAR PUSTAKA}

\section{Referensi Buku}

A. Devito, Joseph. 1997. Komunikasi Antarmanusia. Jakarta: Professional Books.

Ahmad, Rohani. 2010. Pengelolaan Pembelajaran. Jakarta:PT Rineka Cipta

Bandura, A. 1994. Self Efficiacy encyclopedia of human behavior. San Diego : Academic Press

Budyatna, Muhammad dan Leila Mona Ganiem. 2011.Teori Komunikasi Antar Pribadi. Jakarta: Prenada Media Group.

Bunawan, L. \& Yuwati C,S. 2000. Penguasaan bahasa pada anak tunarungu. Jakarta : Yayasan Santi Rama

Bunawan, L. 2004. Hakekat Ketunarunguan \& Implikasi dalam pendidikan. Jakarta : Yayasan Santi Rama

Carrera, Michael. 2010. Instructional Adaptations for Students with diverse needs. New Jersey: New Jersey comprehensive health education and physical education curriculum framework

Direktorat Pendidikan Luar Biasa (DPLB). 2004. Pedoman Penyelenggaraan Pendidikan Inklusi. Jakarta : Direktorat Pendidikan Luar Biasa.

Effendi. 2008. Pengantar Psikopedagogik anak berkelainan. Jakarta : PT Bumi Aksara 
Effendy. \& Uchana, Onong. 2005. Ilmu Komunikasi : Teori dan Praktek. Bandung : PT Remaja Rosdakarya

Gudykunst, B. William, \& Kim, Y. Y. 2003. Communicating With Strangers Fourth Edition. new york: Mac Graw Hill.

Hallahan, D.P . Kauffman, J . 1991. Exceptionality Children Introduction to Special Education 5th ed. New Jersey: Prentice Hall International, Inc.

Kriyantono, Rachmat.2006. Teknik Praktis Riset Komunikasi. Jakarta:Kencana

Hornby, Garry. 2015. Inclusive Special Education : Development of a new theory for the education of children with special educational needs and disabilities. London : NASEN

Kim, J.H., 2015. Understanding narrative inquiry: The crafting and analysis of stories as research. Sage publications.

Kirk, Samuel., Gallagher, J.J . 2010. Educating Exceptional Children. California : Houghton Mifflin Company.

Kriyantono, Rachmat.2006. Teknik Praktis Riset Komunikasi. Jakarta:Kencana

Mangunsong, Frieda. 1998. Psikologi dan Pendidikan Anak Luar Biasa. LPSP3 Universitas Indonesia.

Moleong J.Lexy. 2011. Metode Penelitian KualitatifEdisi Revisi. Bandung: PT. Remaja Rosdakarya Offset.

Moleong, Lexy J. 2007. Metodologi Penelitian Kualitatif. Bandung : Rosdakarya

Murni Winarsih. 2007. Intervensi Dini Bagi Anak Tunarungu dalam Pemerolehan Bahasa. Departemen Pendidikan dan Kebudayaan. Direktorat Jenderal Pendidikan Tinggi. Direktorat Ketenagaan

Richard West, Lynn H.Turner. 2008 Pengantar Teori Komunikasi: Analisis dan Aplikasi (Buku 2) (Edisi 3) Jakarta: Salemba Humanika

Rogoff, Barbara. 2003. The Cultural Nature of Human Development. Oxford : Oxford University Press

Scott, Barbara J. 1998. Implementing Instructional Adaptations for Students wit Disabilities in Inclusive Classrooms. California : Sage Publication

Shaddock, Anthony. 2007. Students with disabilities in mainstream classrooms. Canberra : Commonwealth of Australia

Stinson, M.S \& Lang, H.L . 1994. The Potential Impact on deaf students of the full inclusion movement. Washington D.C : Gallaudet Research Institute, Gallaudet University

Suranto, AW. 2011. Komunikasi Interpersonal. Yogyakarta : Graha Ilmu.

Vygotsky. 1978. Interaction Between Learning and Development. Newyork : Scientific American Book 


\section{Referensi Jurnal}

Adwiasa, Novan dan Muryantinah. 2013. Perbedaan Penyesuaian diri antara Siswa Tunarungu di Sekolah Inklusi dan di Sekolah Luar Biasa. Jurnal Psikologi Pendidikan dan Perkembangan Vol.2, No.1, hlm 1-6

Alwis, C. 2005. Children With hearing Impairment in regular Classroom. Sri Lanka Journal of Educational Research, 9,hlm. 45-69

Barker, David H. 2009. Predicting Behavior Problems in deaf and hearing children: The Influences of Language, attention, and parent-child communication. Cambridge University Press, hlm 373392

Connelly, F., \& Clandinin, D. 1990. Stories of Experience and Narrative Inquiry. Educational Researcher, 19(5), 2-14.

Dammeyer, Jesper. 2009. Psychosocial development in a Danish population of children with cochlear impalnts and deaf and hard-of-hearing children. Journal of Deaf Studies and Deaf Education, hlm. 50-58

Guba, E.G \& Lincoln Y.S, 1981. Effective Evaluation. Improving The Usefulness Of Evaluations Result Through Responsive And Naturalistic Approaches. Jassey-BassInc. Publisher, hlm. 107

Hasan, Sofy Ariany dan Muryantinah. 2014. Hubungan antara dukungan sosial Teman Sebaya dengan Penyesuaian diri Siswa Tunarungu di Sekolah Inklusi. Jurnal Psikologi Pendidikan dan Perkembangan Vol. 3, no. 2. Hlm 128-135

Hernawati, T., 2007. Pengembangan Kemampuan Berbahasa dan Berbicara Anak Tunarungu. Jurnal JASSI_anakku, 7(1), hlm.101-110.

Nunes, Terezinha dan Pretzlik, Ursula . 2001. DeafChildren's social Relationships in mainstream schools. Deafness and Education International 3(3) Whurr Publishers. Hlm. 123- 136

Rachmawati, Dian dan Sarwindah, Dwi. 2010. Penyesuaian Sosial Remaja Tunarungu yang bersekolah di Sekolah Umum. INSAN Vol.12 No. 03 hlm. 138-152

Stinson, Michael S dan Antia, Shirin D. 1999. Considerations in educating deaf and hard of hearing students in inclusive settings. Oxford University Press, hlm. 171-177

Referensi Tesis dan Skripsi

Makhmudayeva, Shynar. 2016. Secondary school ESL teachers'attitudes, understanding and concerns about implementation of inclusive education in Kazakhstan. Thesis. Charles University Prague

Suleymanov, Farid. 2014. Academic Achievements of Students with Special Needs in Inclusive Education. Thesis. University of Oslo 


\section{Referensi Internet}

Hasil sensus penduduk akhir 2015 BPS .http://bps.go.id/SUPAS-2015 rev diunduh pada tanggal 30 Agustus 2017 pukul 10.00

Kemendikbud Tahun ini akan Bangun 11 Sekolah Luar Biasa. https://www.kemdikbud.go.id/main/ blog/2017/02/kemendikbud-tahun-ini-akan-bangun-11-sekolah-luar-biasa. Diunduh pada tanggal 25 agustus 2017 pukul 13.05 wib

Sekolah Inklusi dan Pembangunan SLB Dukung Pendidikan Inklusi https://www.kemdikbud.go.id/ main/blog/2017/02/sekolah-inklusi-dan-pembangunan-slb-dukung-pendidikan-inklusi. Diunduh pada tanggal 25 Agustus 2017 pukul $13.20 \mathrm{wib}$

Siswa Tunarungu Juara 1 UN di Sekolah Umum. https://news.okezone.com/read/2012/05/30/373/ 638074/siswa-tuna-rungu-juara-1-un-di-sekolah-umum. Diunduh pada tanggal 27 agustus pukul 14.08 